\title{
Contraceptive choice for young people
}

\author{
Rebecca Say, Diana Mansour
}

\begin{abstract}
Background and methodology Giving young women access to newer contraceptives such as the combined contraceptive patch, combined contraceptive vaginal ring and single-rod implant may help reduce teenage pregnancies. However, little is known about young people's attitudes towards these contraceptives. This cross-sectional survey, using a self-completion questionnaire, aimed to explore young people's attitudes towards these contraceptives in order to develop understanding of the choices they make about contraception. Participants were a self-selecting sample of young women attending contraception clinics in Newcastle upon Tyne, UK. Statistical analysis was carried out using appropriate univariate tests. Qualitative analysis involved identification of key themes, which were continuously challenged by looking for conformity and variation and by identifying disconfirming cases.
\end{abstract}

Results The majority of the 127 participants had no prior knowledge of the patch, vaginal ring or implant. Interest in using these contraceptives was low. Associations were found between their attitude towards using them and the participants' age, experience of pregnancy scares, experience of unplanned pregnancies and prior knowledge of the contraceptives. Six major themes emerged relating to the advantages and disadvantages of these contraceptives and included convenience, effectiveness, safety along with side effects, invasiveness and discretion.

Discussion and conclusions Young people's knowledge of and attitudes towards these contraceptives was variable and may have been influenced by experience and access to information. Themes identified from perceptions of these contraceptives are useful in developing understanding of what young people look for in contraceptives. Health professionals should provide information on these themes when assisting young people in making informed decisions about contraception.

Keywords combined hormonal patch, combined hormonal vaginal ring, long-acting reversible contraceptives, single rod implant, young people

J Fam Plann Reprod Health Care 2009; 35(2): 81-85

(Accepted 3 November 2008)

\section{Introduction}

The UK continues to have the highest teenage pregnancy rate in Europe. ${ }^{1}$ Access for young people to effective contraception is a key factor in reducing the number of teenage pregnancies. ${ }^{2}$ Currently, the most commonly used method of contraception for adolescents is the combined oral contraceptive pill (COC). ${ }^{1}$ However, lower compliance rates and higher failure rates have been reported for the $\mathrm{COC}$ in this age group, leaving many young women at risk of pregnancy. 1,3

Health professionals have suggested that use of alternative contraceptives including long-acting reversible contraception (LARC) such as the single-rod implant (Implanon ${ }^{\circledR}$ ) may benefit young women ${ }^{1,4}$ and this may also be true of newer methods of contraception such as the combined contraceptive patch (Evra $\left.{ }^{\circledR}\right)^{1}$ and the combined contraceptive vaginal ring (NuvaRing ${ }^{\circledR}$ ).

Nevertheless, little is known about what teenagers themselves think about these methods of contraception. Previous research in the USA suggested that between $70 \%$ and $80 \%$ of adolescent girls were interested in using the older, multi-rod contraceptive implant, Norplant ${ }^{\circledR}$, viewing it as an effective and convenient method of contraception, with potential side effects, cosmetic and procedural features seen as its major disadvantages. ${ }^{5}$

However, there were limitations to this study and no

Northern Deanery, Newcastle upon Tyne NHS Hospitals Trust, Newcastle upon Tyne, UK

Rebecca E Say, MBBS, BMedSci, Academic Clinical Fellow in Obstetrics and Gynaecology

\section{Newcastle Contraception and Sexual Health Services, Newcastle upon Tyne, UK \\ Diana Mansour, FRCOG, FFSRH, Consultant}

Correspondence: Dr Diana Mansour, Graingerville Clinic, Newcastle General Hospital, Westgate Road,

Newcastle upon Tyne NE4 6BE, UK.

E-mail: diana.mansour@newcastle-pct.nhs.uk

\section{Key message points}

- Young people's knowledge of and interest in using the contraceptive patch, vaginal ring and implant were generally low.

- Participants' attitudes towards using these contraceptive methods were associated with their age, experience of pregnancy scares, experience of unplanned pregnancies and prior knowledge.

- Six themes emerged relating to the advantages and disadvantages of these contraceptives including convenience, effectiveness, safety along with side effects, invasiveness and discretion.

research has assessed the attitudes of young people towards newer methods of contraception. Therefore, this study aimed to explore the attitudes of young people towards the patch, vaginal ring and implant in order to develop understanding of the choices that young people make about contraception. At the time of the study the implant was available from local contraception and sexual health clinics and general practices but the patch and vaginal ring were not.

\section{Methods}

A cross-sectional survey was carried out using a selfcompletion questionnaire. All young people (aged under 25 years) attending three young people's contraception and sexual health clinics in Newcastle upon Tyne, UK over a 3week period were approached and asked to read the information leaflet and fill in an anonymous questionnaire if they wanted to participate.

The questionnaire was developed for the purposes of this study. It consisted of an introductory section seeking information regarding current contraceptive use followed by three sections concerning the patch, vaginal ring and implant. Participants were first asked if they had heard of the particular method. A brief description of the method was then given. They were then asked if they would wish to use that method and what they perceived as its 
advantages and disadvantages to them personally. Limited demographic information was also collected.

\section{Statistical analysis}

Statistical analysis was carried out using Statistical Package for the Social Sciences (SPSS) (Chicago, IL, USA) using appropriate univariate tests where vales of $p<0.05$ were statistically significant.

\section{Qualitative analysis}

The first stage of qualitative analysis involved detailed reading and re-reading of qualitative answers for familiarisation with the content and identify key themes. These were then systematically coded to enable analysis of each category and how the categories related to each other. These were then challenged by looking for conformity and variation and by identifying disconfirming cases. Thus alternative explanations were continuously sought. Qualitative data were reconciled with the quantitative results and answers from the clinic group were compared with answers from the school group.

\section{Ethical approval}

Ethical approval for the study was granted by Newcastle and North Tyneside Joint Ethics Committee.

\section{Results}

A total of 127 questionnaires were completed. The method of questionnaire distribution was designed to ensure anonymity, which meant a response rate could not be calculated and no information is known about non-respondents.

\section{Description of participants}

All 127 participants were female. Their age range was 13-21 (mean, 16.62) years.

Ten $(7.9 \%)$ participants had experienced an unplanned pregnancy with one $(0.8 \%)$ participant experiencing two unplanned pregnancies. Sixty-eight (53.5\%) participants had experienced a pregnancy scare and $21(16.5 \%)$ had experienced more than one scare.

The majority of participants had no prior knowledge of the patch, vaginal ring or implant (Table 1).

Those participants who reported having prior knowledge of these contraceptive methods reported a number of different sources for this information: family members, friends, boyfriend, school/sixth form college, the media (magazines, newspapers, the news, television, radio) and health professionals (doctors, contraception and sexual health clinics, leaflets).

Interest in using these contraceptives varied but was generally low. The patch was the most popular and the vaginal ring least popular (Table 2).

In order to generate hypotheses about why young peoples' attitudes towards these contraceptives may vary,

Table 1 Participants' prior knowledge of the patch, vaginal ring and implant

\begin{tabular}{llr}
\hline Contraceptive & $\begin{array}{l}\text { Prior knowledge } \\
\text { of contraceptive }\end{array}$ & $\begin{array}{l}\text { Participants } \\
\text { [n (\%)] }\end{array}$ \\
\hline Patch & Yes & $19(15.0)$ \\
& No & $106(83.5)$ \\
Vaginal ring & Blank & $2(1.5)$ \\
& Yes & $4(3.2)$ \\
& No & $115(90.5)$ \\
Implant & Blank & $8(6.3)$ \\
& Yes & $50(39.4)$ \\
& No & $65(51.2)$ \\
& Blank & $12(9.4)$ \\
\hline
\end{tabular}

Table 2 Participants' attitude towards using the patch, vaginal ring and implant

\begin{tabular}{|c|c|c|}
\hline Contraceptive & $\begin{array}{l}\text { Preference for } \\
\text { using contraceptives }\end{array}$ & $\begin{array}{l}\text { Participants } \\
{[n(\%)]}\end{array}$ \\
\hline Patch & $\begin{array}{l}\text { Yes } \\
\text { Possibly } \\
\text { No } \\
\text { Blank }\end{array}$ & $\begin{array}{rr}47 & (37.0) \\
29 & (22.8) \\
49 & (38.6) \\
2 & (1.6)\end{array}$ \\
\hline Vaginal ring & $\begin{array}{l}\text { Yes } \\
\text { Possibly } \\
\text { No } \\
\text { Blank }\end{array}$ & $\begin{array}{rr}7 & (5.5) \\
8 & (6.3) \\
97 & (76.4) \\
15 & (11.8)\end{array}$ \\
\hline Implant & $\begin{array}{l}\text { Yes } \\
\text { Possibly } \\
\text { No } \\
\text { Blank }\end{array}$ & $\begin{array}{ll}34 & (26.8) \\
14 & (11.0) \\
60 & (47.2) \\
19 & (15.0)\end{array}$ \\
\hline
\end{tabular}

associations between their preference for using them and the participants' age, experience of a pregnancy scare, experience of an unplanned pregnancy and prior knowledge of the contraceptive were investigated using univariate analysis.

Participants who stated that they would wish to use the patch were slightly younger (median age, 16 years) than those who stated they would not (median age, 17 years; $p=0.014$ Kruskal-Wallis test). There was no association between age and interest in the vaginal ring or implant.

Participants who had experienced a pregnancy scare were more likely to wish to use the patch and implant but less likely to wish to use the vaginal ring than those who had not experienced a pregnancy scare (patch 50.8\% compared with $24.1 \%$, implant $33.9 \%$ compared with $28.0 \%$, vaginal ring $5.0 \%$ compared with $8.0 \% ; p<0.0001$, Chi-square test).

Participants who had experienced an unplanned pregnancy were more likely to wish to use the vaginal ring and implant but were less likely to wish to use the patch than participants who had not experienced an unplanned pregnancy (vaginal ring $25.0 \%$ compared with $7.8 \%$, implant $62.5 \%$ compared with $28.3 \%$ and patch $33.3 \%$ compared with $38.6 \% ; p<0.0001$, Chi-square test).

Participants with prior knowledge of the patch were more likely to wish to use it than those with no prior knowledge $(52.6 \%$ compared with $35.3 \%$; $p<0.0001$, Chisquare test). Participants with prior knowledge of the vaginal ring were more likely to prefer not to use it than participants with no prior knowledge (100\% compared with $86.1 \%$; $p<0.0001$, Chi-square test). Participants with prior knowledge of the implant had a slight increase in preference to use it compared with those who did not (32.2\% compared with $31.0 \% ; p<0.0001$, Chi-square test).

\section{Qualitative analysis}

Through the process of systematic coding, six major themes emerged relating to the advantages and disadvantages of the patch, vaginal ring and implant: convenience, effectiveness, safety, side effects, invasiveness and discretion. However, there was variation in participants' perceptions of the contraceptives.

Many participants viewed them as convenient because they had to be changed infrequently (Box 1). They contrasted this with the perceived difficulty of taking the COC.

However, some participants felt that the patch and vaginal ring had to be changed too frequently, particularly in comparison with other contraceptives such as DepoProvera ${ }^{\circledR}$ (Box 2). Thus, while they may be more convenient than the COC they may not compare as favourably with other long-acting reversible contraceptives. 
Box 1: Representative quotations for the theme of convenience

Patch

Convenient - don't have to worry about it [like pill].

It sounds OK for people who forget to take their pill often.

Vaginal ring

It lasts three weeks without having to worry about contraception. No need to worry each day about taking a pill.

Implant

Long-term contraception without having to worry day to day You don't have to remember to take your pill.

Box 2: Further representative quotes for the theme of convenience

Patch

Got to keep changing it.

Have to change more frequently than injection.

Vaginal ring

You have to remove and insert it frequently.

More confusing than Depo.

Implant

May forget when to have it again.

If you forgot to have it removed.

Furthermore, while some participants considered the length of action of the implant to be advantageous, others felt that this might be a disadvantage either because they might forget when to have it changed or because they might wish to start a family sooner. It is unclear whether this latter concern was because they were unaware they could have the implant removed should they wish to become pregnant. Further comments included:

How long it will take to come out of the system?

If you want to get pregnant within three years you can't.

Three years is too long.

There was also variation in participants' perceptions of the effectiveness of these contraceptives, with some participants perceiving them as highly effective and others as less effective than other contraceptives (Box 3). Previous research with adults has also emphasised the importance of effectiveness and revealed that women underestimated the effectiveness of the contraceptive implant (but did not consider the patch or vaginal ring) ${ }^{6}$ Perhaps this variation reflects lack of knowledge and possible misconceptions regarding the efficacy of these relatively new contraceptives, and that young people would find information regarding efficacy useful.

One participant was concerned that because the implant was new she could not be sure of its efficacy. However, some participants suggested that an advantage of the vaginal ring was having a new alternative method. Further comments about the these methods included:

Box 3: Representative quotations for the theme of
effectiveness
Patch
Reliable.
May not be as effective as other contraceptives.
Vaginal ring
More reliable.
Might not be as effective.
Implant
It is $99.9 \%$ safe.

Box 3: Representative quotations for the theme of

Patch

Reliable.

May not be as effective as other contraceptives.

It is $99.9 \%$ safe.
It has not been around long enough to trust completely. It's [vaginal ring] a new option.

A particular concern was that the patch might 'fall off', so it will be important for health professionals to reassure young people that research has shown detachment is rare. ${ }^{7}$ Similarly, they may need to be reassured that the vaginal ring is unlikely to fall out. ${ }^{8}$ As these comments were often phrased as questions it suggests that participants wanted more information. These comments included:

Patch may fall off

What if it comes off and you don't notice?

Showers?'

It [vaginal ring] might fall out.

It was perhaps reassuring that participants identified lack of protection from sexually transmitted infections (STIs) as a disadvantage of all three contraceptives.

\section{It won't protect against STIs.}

Participants were also concerned about the side effects of these contraceptives (Box 4). They had some awareness of likely side effects (e.g. skin irritation for the patch and menstrual disturbance for the implant) but had some misconceptions (e.g. internal damage from the vaginal ring) and some general concerns (e.g. weight gain for all three methods).

The phrasing of perceived disadvantages as conditional suggests that some participants desired further information. It would be useful to clarify what side effects are acceptable to young people as research with older women has shown variation in the severity of side effects, such as weight gain, which would be tolerated. ${ }^{6}$

The invasiveness of the vaginal ring and implant was a common theme in the disadvantages (Box 5). For the vaginal ring, invasiveness was perceived both in terms of physical discomfort and potential embarrassment with the procedure of inserting the ring. For the implant, participants were concerned that the procedure would be painful or described a fear of needles. This suggests that there may be some young people who will not tolerate the procedures involved and may explain why these methods were less popular than the patch.

Box 4: Representative quotations for the theme of safety

and side effects

Patch

Skin irritation.

It may be uncomfortable.

If it makes you gain weight.

Vaginal ring

It may be uncomfortable and cause internal problems.

May put weight on you.

Implant

Don't know when you have a period all the time.

Might leave a scar.

You gain weight.

Box 5: Representative quotations for the theme of invasiveness

Vaginal ring

It would feel funny.

I wouldn't want it up me.

Embarrassing to insert.

Some girls will not feel comfortable with this process.

Implant

Implant may hurt.

I hate injection type things. 


Box 6: Representative quotations for the theme of discretion
Patch
Unattractive.
Looks stupid.
If parents see it.
Not visible.
Vaginal ring
Discreet.
Can't see it.
Implant
It's discreet.
Unseen.
You may be able to see it under the skin.

Nevertheless, a study of user acceptability of the vaginal ring with an adult sample showed that over $95 \%$ of women found the ring easy to insert or remove which may suggest that the vaginal ring may be more acceptable when the procedure has been experienced. ${ }^{9}$ Also, some participants thought that it would have to be inserted in a clinic so, perhaps with reassurance that they were in control, it may be seen as less invasive. Furthermore, previous research suggested that while procedural features were seen as a potential disadvantage of implants, they did not make implants unacceptable to adolescents. ${ }^{5}$

An advantage the vaginal ring and implant had over the patch was that they were seen as discreet, with the visibility of the patch seen as a disadvantage (Box 6). For some participants the appearance was a disadvantage for aesthetic reasons. For others it was because it was visible and other people may become aware they were using it. This might be a particular problem in this age group for those who wish to use an effective method of contraception but do not want their parents to be aware that they are sexually active. However, one participant felt that an advantage of the patch was that it could be hidden. In contrast, the vaginal ring and implant were generally viewed as discreet, although some participants were concerned that an implant may be seen.

\section{Discussion}

This study explored the attitudes of young people towards the contraceptive patch, vaginal ring and the single-rod implant. The majority of participants did not have prior knowledge of the patch, vaginal ring or implant. Previous research in the USA found that $56 \%$ of adolescent participants had prior knowledge of the older multi-rod implant Norplant, perhaps reflecting differences between the study populations or the novelty of the single-rod implant..$^{5}$

The diversity in the sources of information about these contraceptives is reassuring since it is beneficial for adolescents to receive information about contraception in a variety of settings yet it emphasises the need for health professionals to ensure that alternative information providers have access to good quality information and are kept informed of advances such as new contraceptive methods.

Interest in using these new contraceptives was variable but generally low. While no research has been carried out into young people's attitudes to the patch or vaginal ring, previous research in the USA suggested that between $70 \%$ and $80 \%$ of adolescent girls were interested in using the older contraceptive implant, Norplant. ${ }^{5}$ This difference may reflect the greater amount of information provided in the North American study, local financial incentives available in the USA at that time or differences between the populations.

This study found statistically significant associations between participants' attitude towards using these contraceptives and their age, experience of a pregnancy scare, experience of an unplanned pregnancy and prior knowledge of the contraceptive.

Participants who wanted to use the patch were slightly younger than those who did not. The reasons for this are unclear but may reflect potential confounding factors such as access to information and experience of other contraceptives.

Participants who had experienced a pregnancy scare were more likely to wish to use the patch and implant than participants who had not. It is perhaps unsurprising that young people who had probably not had access to contraception or who had not been using it effectively would wish to use methods that were generally seen as highly effective and convenient.

Participants who had experienced an unplanned pregnancy were more likely to wish to use the vaginal ring and implant than those who had not. Again this may reflect a desire to use an effective contraceptive following an experience of inadequate contraception. Previous research suggested that prior pregnancy was the most important characteristic that determined whether or not adolescents wanted to use the older multi-rod implant, Norplant. 5 Participants who had experienced an unplanned pregnancy were less likely to wish to use the patch than participants who had not. Perhaps the patch is seen as a new technology using a novel but unreliable delivery system and therefore not so effective.

Participants with prior knowledge of the contraceptives were more likely to have a firm preference of either wishing to use or wishing not to use these methods. They may have felt they already had enough information to make the decision. It would have been interesting to know the extent and accuracy of their prior knowledge and its effects when faced with new contraceptive method information.

The six major themes identified in the qualitative analysis were useful in developing an understanding of what young people look for in a contraceptive. It seems that for these young people the ideal contraceptive would be one which is simple to take, difficult to forget, highly effective, safe with minimal side effects, minimally invasive and discreet. It is important for health professionals to provide information on all these themes when assisting a young person in making an informed decision about contraception.

There were a number of limitations to this study including the cross-sectional design, a self-selecting sample, limited external validity and univariate analysis. While the questionnaire was kept purposefully short to encourage participation, this meant that qualitative answers could only be relatively short and data on a limited number of variables could be collected. Also, only very limited information was given about the contraceptives, which was interesting as it revealed some misconceptions but may mean that the results may not reflect the preferences the participants would have if they had had access to more information. Only the implant was available locally at the time of the study, which may also have influenced the results. Further research is needed to overcome the limitations of this study and numerous related issues could be investigated. It would be useful to perform a cohort study to investigate how young people's attitudes towards different contraceptive methods change over time with new experiences and access to information.

Nevertheless, this is the first study exploring the attitudes of young people towards the contraceptive patch, vaginal ring and the single-rod implant. Hopefully the knowledge gained will help us to meet the contraceptive needs of young people. 
Statements on funding and competing interests

Funding Diana Mansour has received honoraria and expenses for attendance at advisory boards, lectures and sponsored symposia for Organon Laboratories (part of the Schering-Plough Corporation). Competing interests None identified.

\section{References}

1 Vanhegan G. Contraception in the under-16s; issues of confidentiality and choice of methods. The Obstetrician and Gynaecologist 2008; 10: 22-26.

2 Anonymous. Contraception in teenagers. Drug Ther Bull 2002; 40: 92-95.

3 Potter LS. How effective are contraceptives? The determination and measurement of pregnancy rates. Obstet Gynecol 1996; 88: 13S-23S.

4 National Institute for Health and Clinical Excellence. Long-Acting Reversible Contraception (Clinical Guideline CG30). October 2005. http://www.nice.org.uk/Guidance/CG30/ Guidance/pdf/English [Accessed 5 July 2008].
5 Dabrow S, Merrick CL, Conlon M. Adolescent girls' attitudes toward contraceptive subdermal implants. J Adolesc Health 1995; 16: 360-366.

6 Edwards JE, Oldman A, Smith L, McQuay HJ, Moore RA. Women's knowledge of, and attitude to, contraceptive effectiveness and adverse health effects. Br J Fam Plann 2000; 26: 73-80.

7 Faculty of Family Planning and Reproductive Health Care Clinical Effectiveness Unit. New Product Review (September 2003). Norelgestromin/ethinyl oestradiol transdermal contraceptive system (Evra ${ }^{\circledR}$ ). J Fam Plann Reprod Health Care 2004: 30: 43-45.

8 N Shimoni, C Westhoff. Review of the vaginal contraceptive ring (NuvaRing ${ }^{\circledR}$ ). J Fam Plann Reprod Health Care 2008; 34: 247-250.

9 Novak A, de la Loge C, Abetz L, van der Meulen E. The combined contraceptive vaginal ring, NuvaRing: an international study of user acceptability. Contraception 2003. 67: 187-194.

\section{ARTICLE UPDATE \\ UK provision for removal of non-palpable contraceptive implants, Mansour D, J Fam Plann Reprod Health Care 2009: 35(1): 3-4}

Since the above-mentioned article appeared in print in the January 2009 issue of the Journal we have been notified about a number of additional UK referral centres. Details of these centres have been added to the table below such that the listing is current as of April 2009. Organon Laboratories (now a part of Schering-Plough) keep an updated list of all the referral centres that have agreed to take referrals through the company. They can be contacted by calling 01707363636 and asking for Medical Information. Journal readers should note that there may be other centres in their locality that are performing deep removals but that are not included on the list held by the company.

Table 1 Referral sites in the UK for removal of deep/non-palpable contraceptive implants

\begin{tabular}{|c|c|}
\hline Name of contact & Address \\
\hline Dr Gillian Flett & 13 Golden Square, Aberdeen AB10 1RH \\
\hline Dr Kate Weaver & 18 Dean Terrace, Edinburgh EH4 1NL \\
\hline Dr Audrey Brown & Sandyford Initiative, 2-6 Sandyford Place, Glasgow G3 7NB \\
\hline Dr Diana Mansour & Graingerville Clinic, Newcastle General Hospital, Westgate Road, Newcastle upon Tyne NE4 6BE \\
\hline Dr Sandra McDermott & Brae Clinic, Waterside Health and Social Care Centre, 127-147 Spencer Road, Londonderry BT47 6AQ \\
\hline Dr Kate Guthrie & Conifer House, 32-36 Prospect Street, Hull HU3 8PX \\
\hline Dr Babatunde Gbolade & St James University Hospital, Beckett Street, Leeds LS9 7TF \\
\hline Dr Steve Chadwick & Windhill Green Medical Practice, 2 Thackley Old Road, Shipley BD18 1QB \\
\hline Dr Paula Briggs & May Logan Centre, 294 Knowsley Road, Bootle L20 5DQ \\
\hline Dr Cathy Tupper & Department of Obstetrics and Gynaecology, Royal Lancaster Infirmary, Lancaster LA1 4RP \\
\hline Dr Nathan Acladious & Department of Sexual Health, Royal Bolton Hospital, Minerva Road, Farnworth, Bolton BL4 OJR \\
\hline Dr Suzanne Kirkwood & $\begin{array}{l}\text { Gynaecology Department, Countess of Chester Hospital, The Countess of Chester Health Park, } \\
\text { Chester CH2 } 1 \text { UL }\end{array}$ \\
\hline Dr Stephen Searle & Sexual Health Services @ Wheatbridge, Chesterfield S40 2AB \\
\hline Dr Kate Nash & Central Family Planning Clinic, Grove Road, Norwich NR1 3RH \\
\hline Dr Martyn Walling & Lincolnshire PCT, Orchard House, Greyleas, Sleaford NG34 8PP \\
\hline Dr Emeka Oloto & $\begin{array}{l}\text { Clinical, Training and Administrative Headquarters, St Peters Health Centre, Sparkenhoe Street, } \\
\text { Leicester LE2 0TA }\end{array}$ \\
\hline Dr Kulsum Jaffer & St Patrick's Centre for Community Health, Frank Street, Highgate, Birmingham B12 OYA \\
\hline Dr Mike Newman & Kettering General Hospital, Rothwell Road, Kettering NN16 8UZ \\
\hline Dr Jo Hoddinott & Sexual Health Clinic, Pond Street, Carmarthen SA31 1RT \\
\hline Dr Terry McCarthy & Llanyrafon House, Llanfrechfa Grange Hospital, Cwmbran, Torfaen NP44 8YN \\
\hline Dr Sharon Bodard & Central Hill Clinic, Tower Hill, Bristol BS2 0JD \\
\hline Dr Lynsey Dunkley & The Quay to Health, The Quays Swimming and Diving Complex, 27 Harbour Parade, Southampton SO15 1BA \\
\hline Dr Graham Davies & Ella Gordon Unit, St Mary's Hospital, West Wing, Milton Road, Portsmouth PO3 6AD \\
\hline Dr Janet Michaelis & $\begin{array}{l}\text { Contraception and Sexual Health, Specialist Implanon Removal Clinic, Durrington Health Centre, } \\
\text { Durrington Lane, Worthing, West Sussex BN13 2RX }\end{array}$ \\
\hline Dr Caroline Marfleet & Colchester General Hospital, Turner Road, Colchester, Essex CO4 5JL \\
\hline Dr Elizabeth Tanner & 26 Old Dover Road, Canterbury, Kent CT1 3JH \\
\hline Dr Tina Peers & Department of Contraception and Sexual Health, Maple House, Canada Avenue, Redhill RH1 5RH \\
\hline Dr Liz Azzopardi & The Garden Clinic, Upton Hospital, Albert Street, Slough SL1 2BJ \\
\hline Dr Janet Wright & Fernville Surgery, Midland Road, Hemel Hempstead HP2 5BL \\
\hline Dr Jane Dickson & Market Street Health Centre, Market Street, Woolwich SE18 6QF \\
\hline Dr Katherine Creamer & Streatham Hill Sexual Health Centre, 41a-c Streatham Hill, London SW2 4TP \\
\hline Dr Kate Paterson & Raymede Clinic, St Charles Hospital, Exmoor Street, Kensington, London W10 6DZ \\
\hline Dr Paul O’Brien & Raymede Clinic, St Charles Hospital, Exmoor Street, Kensington, London W10 6DZ \\
\hline Dr Chris Wilkinson & Margaret Pyke Centre, 73 Charlotte Street, London W1T 4PL \\
\hline Dr May Erskine & Homerton University Hospital NHS Foundation Trust, Homerton Row, London E9 6SR \\
\hline
\end{tabular}

The referral centres have been informed that patients will be referred by letter, and indeed this is their preferred method of communication. The list of referral centres is subject to change, and therefore doctors should contact Organon Laboratories (now a part of Schering-Plough) for details of their nearest centre. 